\title{
Characteristics of strontium isotopes and their implications in the Qixing Cave of Guizhou, China
}

\author{
ZHU XiaoLong $^{1,2}$, WANG ShiJie ${ }^{1 *} \&$ LUO WeiJun $^{1}$ \\ ${ }^{1}$ State Key Laboratory of Environmental Geochemistry, Institute of Geochemistry, Chinese Academy of Sciences, Guiyang 550002, China; \\ ${ }^{2}$ Graduate University of Chinese Academy of Sciences, Beijing 100049, China
}

Received August 19, 2010; accepted December 1, 2010

\begin{abstract}
The strontium isotopic compositions $\left({ }^{87} \mathrm{Sr} /{ }^{86} \mathrm{Sr}\right)$ of samples including soils, bedrock, soil waters, drip waters and their corresponding speleothems in the Qixing Cave (QXC), Guizhou Province, China, were systemically measured and analyzed. The results indicate that there are significant $\mathrm{Sr}$ isotopic differences among samples. The mean ${ }^{87} \mathrm{Sr} /{ }^{86} \mathrm{Sr}$ ratios in drip water for the samples $1^{\# \text {, }}$ $4^{\#}$ and $9^{\#}$ were $0.709568,0.709139$ and 0.708761 , respectively, which possibly result from different flow paths, residence times, and other hydrogeological processes in the unsaturated zone overlying QXC. Meanwhile, levels of $40.8 \%, 57.6 \%$ and $72.4 \%$ of Sr in drip waters for $1^{\#}, 4^{\#}$ and $9^{\#}$, respectively, were derived from bedrock dissolution, which was calculated by the mixture model of the two end-members (soil and bedrock). There is, however, no positive correlation between the relative proportion from bedrock dissolution $\left(\delta^{13} \mathrm{C}\right.$ value is $1.8 \%$ ) and drip water $\delta^{13} \mathrm{C}_{\mathrm{DIC}}$ values. The mean drip water $\delta^{13} \mathrm{C}_{\mathrm{DIC}}$ value in $1^{\#}$ is the heaviest $\left(-4.5 \%\right.$ ) with the lowest contribution rate of bedrock dissolution, whereas the value in $9^{\#}$ is the lightest $(-9.3 \%)$ with the highest contribution rate of bedrock dissolution. The proportion from host rock dissolution in $4^{\#}$ is higher than that in $1^{\#}$ and lower than that in $9^{\#}$, while its mean drip water $\delta^{13} \mathrm{C}_{\text {DIC }}$ value $\left(-8.6 \%\right.$ ) is higher than that of $9^{\#}$ and lower than that for $1^{\#}$. This suggests that the prior calcite precipitation (PCP) processes in the unsaturated zone overlying the cave are responsible for the $\delta^{13} \mathrm{C}_{\mathrm{DIC}}$ value differences between different drip waters, and not bedrock dissolution. Furthermore, this study also demonstrates that the ${ }^{87} \mathrm{Sr} /{ }^{86} \mathrm{Sr}$ ratios of speleothems in the $1^{\#}$ and $4^{\#}$ mainly reflect the variation in the relative proportions from the soil system (soil water) and bedrock dissolution overlying the cave. It is, therefore, feasible to use the strontium isotopic signals of speleothems as an indicator for soil chemical weathering intensity, and consequently as a monsoon proxy in the study area.
\end{abstract}

strontium isotope, cave drip water, source, prior calcite precipitation (PCP), Qixing Cave of Guizhou

Citation: Zhu X L, Wang S J, Luo W J. Characteristics of strontium isotopes and their implications in the Qixing Cave of Guizhou, China. Chinese Sci Bull, 2011, 56: 670-675, doi: 10.1007/s11434-010-4337-3

In 1990, Avigour et al. [1] first studied the ${ }^{87} \mathrm{Sr} /{ }^{86} \mathrm{Sr}$ ratio of veins and secondary cave calcites in the south of Israel. Because there is no $\mathrm{Sr}$ isotopic fractionation in the processes of carbonate dissolution, transportation and calcite precipitation, the ${ }^{87} \mathrm{Sr} /{ }^{86} \mathrm{Sr}$ signal in speleothem (as stalagmite) has recently become an important indicator for tracing the source and studying changes in paleoclimate and paleoenvironment. For instance, Verheyden et al. [2] attributed the ${ }^{87} \mathrm{Sr} /{ }^{86} \mathrm{Sr}$ variations in a Belgian Holocene speleothem to changes in water residence time and weathering processes.

*Corresponding author (email: wangshijie@ vip.skleg.cn)
They analyzed the climatic and environmental change tendencies during 13-2 ka BP in that area. Li et al. [3] studied the ${ }^{87} \mathrm{Sr} /{ }^{86} \mathrm{Sr}$ ratios in a stalagmite from Heshang Cave in southern Shanxi Province by the mass-balance model, and successfully reconstructed the degree and variation in chemical weathering intensity for the soil overlying the cave. Moreover, Zhou et al. [4] found that the ${ }^{87} \mathrm{Sr} /{ }^{86} \mathrm{Sr}$ ratios of a stalagmite could be used to investigate the atmospheric dust activity and the Asian winter monsoon at the Songjia Cave in northeastern Sichuan Province, China. These results imply that the fluctuation of ${ }^{87} \mathrm{Sr} /{ }^{86} \mathrm{Sr}$ ratios in speleothems could be closely related with changes in 
climate and environment. Although many significant achievements have been made on ${ }^{87} \mathrm{Sr} /{ }^{86} \mathrm{Sr}$ ratio in speleothems, there are few studies about the $\mathrm{Sr}$ isotopic compositions of different components in cave system. It is difficult to distinguish the relative proportions of $\mathrm{Sr}$ from various $\mathrm{Sr}$ sources composed of different $\mathrm{Sr}$ isotopes, and consequently, results can lead to various interpretations as a climate and environment proxy $[2,5,6]$. To understand climate and environment signals from ${ }^{87} \mathrm{Sr} /{ }^{86} \mathrm{Sr}$ ratios in speleothems, it is, therefore, important to monitor and analyze various types of potential $\mathrm{Sr}$ sources and changes. Our previous work has shown that it is difficult to distinguish the relative effects of host rock dissolution and prior calcite precipitation $(\mathrm{PCP})$ processes based on $\mathrm{C}$ isotopic variabilities in drip water in the QXC [7] because both of them could result in the drip water $\delta^{13} \mathrm{C}_{\text {DIC }}$ signal becoming heavier. Here, we attempt to use $\mathrm{Sr}$ isotopes as a tool to distinguish these processes because the PCP process will not interfere with the $\mathrm{Sr}$ isotopic compositions.

In this study, we chose QXC as study site where the stable isotopes, hydrology and hydrochemistry are already known to a certain degree [7-11]. We aim to use the Sr isotopic tool, coupled with other geochemical characteristics of drip water, to trace the sources of cave drip waters/ speleothems. This allowed us to further investigate the effects of hydrogeochemical processes on the $\mathrm{C}$ isotopic signals in drip water, which would provide a fundamental theoretical support for reconstructing paleoclimate from speleothem $\mathrm{Sr}$ isotopes.

\section{Study area, sampling and methods}

\subsection{Study area}

Qixing Cave $\left(25^{\circ} 59^{\prime} \mathrm{N}, 107^{\circ} 16^{\prime} \mathrm{E}\right)$ is located $\sim 1.5 \mathrm{~km}$ of northeast Kaiyou Village, Kaikou Town, Duyun in Guizhou Province, China (Figure 1(a)). The cave's bedrock comprises carboniferous limestone $\left(\mathrm{C}_{1 \mathrm{~b}}-\mathrm{C}_{2 \mathrm{hn}}\right)$ and dolomitic limestone, the thickness of roof overlying the cave is $\sim 50-90 \mathrm{~m}$, and the rock fractures here are not well devel- oped. The overlying soil is relatively continuous, and the soil layer is $6-180 \mathrm{~cm}$, averaging at $\sim 33 \mathrm{~cm}$; the vegetation is of a brushwood type. The climate in this area is largely controlled by the Indian and East Asian monsoons. The mean annual temperature (MAT) is $\sim 16.6^{\circ} \mathrm{C}$, the annual rainfall is $1176 \mathrm{~mm}$, of which $77.5 \%$ falls in monsoonal seasons (April to September), and the average relative humidity of the atmosphere is $77 \%$, according to data from a local weather station between April 2003 and May 2004.

\subsection{Sampling methods}

Samples of soil waters at the top of the cave system were collected using a $100 \mathrm{~mL}$ glass injector from $1 \mathrm{~L}$ boxes buried at a depth of 50 and $100 \mathrm{~cm}$, respectively (Figure 1 (b)). Cave drip waters were collected in the main cave channel, and there were no temperature or moisture differences between each drip water site (Figure 1(c)).The speleothems, corresponding to the drip waters, were precipitated on a glass plate and collected from June 2003 to May 2004; soil and bedrock were collected near the soil waters sample sites. The detailed sampling times of soil water and drip water are listed in Table 1.

\subsection{Test methods}

Samples of soil and bedrock were triturated as fine powders less than $0.075 \mathrm{~mm}$. The powdered samples $(0.1-0.2 \mathrm{~g})$ were placed into a low-pressure Teflon airproofed tin, exposed to a mixture acid of ultrapure $\mathrm{HF}+\mathrm{HNO}_{3}+\mathrm{HCl}$ to achieve acidolysis, and converted into perchlorates by evaporating to dryness. Soil (3-5 g) was triturated to a powder less than $2 \mathrm{~mm}$ and then leached using $1 \mathrm{~mol} / \mathrm{L}$ $\mathrm{NH}_{4} \mathrm{Ac}$, with a buffer solution of $\mathrm{pH}$. The solution was centrifuged and the supernatant was collected in a Teflon tin for enrichment. Finally, they were converted into perchlorates using same method as above for the soil exchangeable $\mathrm{Sr}$ isotope. Soil water and drip water were immediately filtered through $0.45 \mu \mathrm{m}$ Millipore filters, then stored in acid-leached polyethylene bottles and acidified with ultrapure
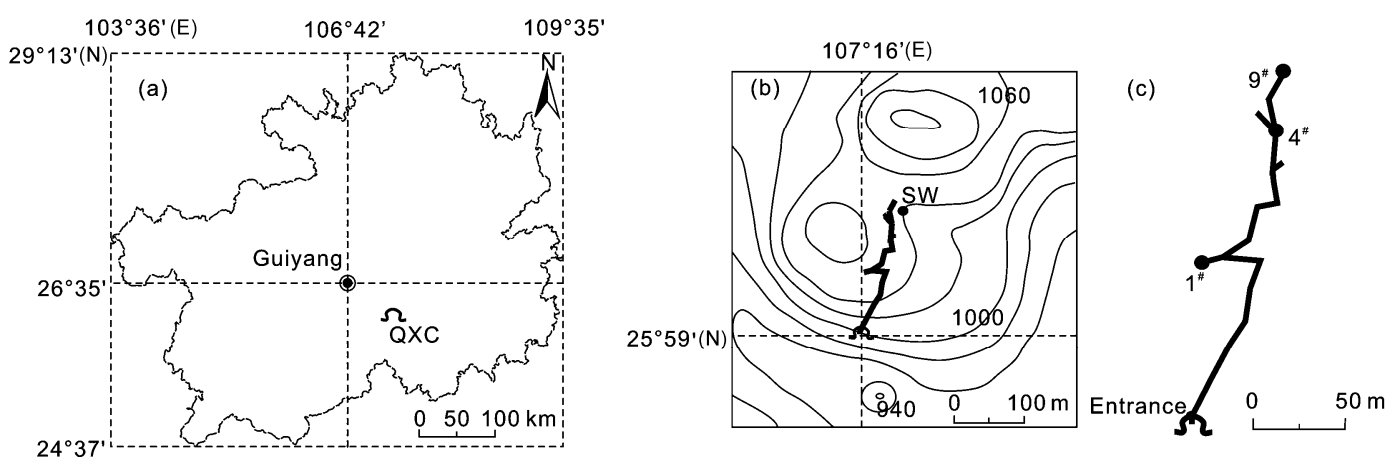

Figure 1 Qixing cave location (a); landform (b), cave orientation and sampling locations (b), (c); SW indicates soil water in (b). $1^{\#}$ indicates No. 1 drip water, and the rest are deduced by analogy in (c). 
$\mathrm{HNO}_{3}$. These samples were then evaporated to dryness in Teflon tins.

The separation of strontium from other major elements for isotopic analysis was achieved using a conventional ion-exchange technique using a Dowex 50W-8X 200-400 mesh resin in $\mathrm{HCl}$ media. The ${ }^{87} \mathrm{Sr} /{ }^{86} \mathrm{Sr}$ ratios were determined using a MC-ICP-MS (multiple collector inductively coupled plasma mass spectrometry, produced by $\mathrm{Nu}$ Instrument Ltd., UK), and normalized for fractionation to ${ }^{86} \mathrm{Sr} /{ }^{88} \mathrm{Sr}=0.1194$. A mean value of 0.710220 was determined by standard analysis of NIST-NBS987 $(2 \sigma= \pm 0.000029$, $n=24$ ) during the measurement period of these samples. The strontium concentrations in soil water and drip water were measured by ICP-MS and the uncertainty was less than $5 \%$

All analytical processes were completed in the State Key Laboratory of Environmental Geochemistry, Institute of Geochemistry, Chinese Academy of Sciences.

\section{Results and discussion}

\section{$2.1{ }^{87} \mathrm{Sr} /{ }^{86} \mathrm{Sr}$ ratios of all types of samples}

The Sr isotopic compositions for different components in the QXC system are shown in Table 1 and Figure 2. We can see that the differences of ${ }^{87} \mathrm{Sr} /{ }^{86} \mathrm{Sr}$ ratios between samples are remarkable. The rainwater and bedrock (limestone) have low radiogenic ${ }^{87} \mathrm{Sr} /{ }^{86} \mathrm{Sr}$ values, while the soil has the most radiogenic ${ }^{87} \mathrm{Sr} /{ }^{86} \mathrm{Sr}$ values, whose dominant mineral is silicate [12]. The variations in ${ }^{87} \mathrm{Sr} /{ }^{86} \mathrm{Sr}$ ratio between the same types of sample are also significant, except for in soil and bedrock (only one sample). The ${ }^{87} \mathrm{Sr} /{ }^{86} \mathrm{Sr}$ values for the soil exchangeable fraction and soil water decrease with increasing soil depth, while the soil water Sr concentrations increase with depth. Meanwhile, cave drip water and the corresponding speleothems are less radiogenic $\left({ }^{87} \mathrm{Sr} /{ }^{86} \mathrm{Sr}\right)$ than those for soil and soil water. Figure 2 indicates that the ${ }^{87} \mathrm{Sr} /{ }^{86} \mathrm{Sr}$ ratios of soil exchangeable components fall between rainwater and soil, whereas the soil water ${ }^{87} \mathrm{Sr} /{ }^{86} \mathrm{Sr}$ values fall between values for the soil exchangeable fraction and soil. The values for cave drip water are all more radiogenic $\left({ }^{87} \mathrm{Sr} /{ }^{86} \mathrm{Sr}\right)$ than limestone, but less than soil water. Their speleothems ${ }^{87} \mathrm{Sr} /{ }^{86} \mathrm{Sr}$ values are similar to the corresponding drip waters.

\section{$2.2{ }^{87} \mathrm{Sr} /{ }^{86} \mathrm{Sr}$ ratios in soil waters}

The previous study indicates in Guiyang that the ${ }^{87} \mathrm{Sr} /{ }^{86} \mathrm{Sr}$ ratios in rainwater range from 0.707934 to 0.709080 , averaging at 0.708219 , with a $\mathrm{Sr}$ concentration of $8.8 \mu \mathrm{g} / \mathrm{L}$ [13]. In the virgin forest in Maolan the ${ }^{87} \mathrm{Sr} /{ }^{86} \mathrm{Sr}$ ratios in rainwater ranged from 0.707463 to 0.712752 , averaging at 0.709058 , with a $\mathrm{Sr}$ concentration of $6.4 \mu \mathrm{g} / \mathrm{L}$ [14]. The QXC is located at the central site between Guiyang and Maolan, with a geological background (karst) and cultivated
Table $1 \mathrm{Sr}$ concentrations and ${ }^{87} \mathrm{Sr} /{ }^{86} \mathrm{Sr}$ ratios of different components in the Qixing Cave

\begin{tabular}{|c|c|c|c|c|c|}
\hline Sample & Date & Depth $(\mathrm{cm})$ & $\mathrm{Sr}(\mu \mathrm{g} / \mathrm{L})$ & ${ }^{87} \mathrm{Sr} /{ }^{86} \mathrm{Sr}$ & $2 \sigma\left(\times 10^{-6}\right)$ \\
\hline \multirow{2}{*}{ Soil } & $2003-10-14$ & $10-20$ & - & 0.727317 & 23 \\
\hline & 2003-10-14 & $30-40$ & - & 0.727417 & 15 \\
\hline \multirow{3}{*}{$\begin{array}{c}\text { Soil ex- } \\
\text { changeable } \\
\text { cation }\end{array}$} & $2003-10-14$ & $0-10$ & - & 0.709704 & 13 \\
\hline & 2003-10-14 & $30-40$ & - & 0.709816 & 26 \\
\hline & $2003-10-14$ & $40-50$ & - & 0.708944 & 15 \\
\hline \multirow{2}{*}{ Soil water } & $2004-05-27$ & 50 & 14.4 & 0.710606 & 34 \\
\hline & 2004-05-27 & 100 & 21.7 & 0.709746 & 12 \\
\hline Bedrock & $2003-10-14$ & & - & 0.708059 & 18 \\
\hline \multirow{4}{*}{$1^{\#}$} & 2003-09-13 & & 14.5 & 0.709513 & 7 \\
\hline & 2003-10-14 & & 14.8 & 0.709567 & 7 \\
\hline & $2004-02-26$ & & 17.8 & 0.709638 & 20 \\
\hline & 2004-05-27 & & 15.4 & 0.709554 & 13 \\
\hline Speleothem & $\begin{array}{l}2003-06-11- \\
2004-05-27\end{array}$ & & - & 0.709561 & 13 \\
\hline \multirow{4}{*}{$4^{\#}$} & 2003-08-14 & & 27.0 & 0.709109 & 7 \\
\hline & 2003-09-13 & & 26.2 & 0.709054 & 5 \\
\hline & $2004-02-26$ & & 23.4 & 0.709193 & 17 \\
\hline & 2004-05-27 & & 22.3 & 0.709201 & 11 \\
\hline Speleothem & $\begin{array}{c}2003-06-11- \\
2004-05-27\end{array}$ & & - & 0.709043 & 28 \\
\hline \multirow{2}{*}{$9^{\#}$} & 2003-08-14 & & 42.9 & 0.708780 & 8 \\
\hline & 2004-05-27 & & 41.8 & 0.708742 & 11 \\
\hline
\end{tabular}

"_" means no data.

style (scattered paddy fields) similar to Guiyang and Maolan. The ${ }^{87} \mathrm{Sr} /{ }^{86} \mathrm{Sr}$ ratio and $\mathrm{Sr}$ concentration in the rainwater can, therefore, be evaluated to be 0.708689 and $7.6 \mu \mathrm{g} / \mathrm{L}$ by the linear interpolation method in the QXC area.

From systemically monitoring the results of oxygen (hydrogen) isotope compositions in a series of samples in the QXC, the soil water originates directly from local precipitation [15], suggesting that rainwater is an important sources for $\mathrm{Sr}$ in the soil water. Therefore, the $\mathrm{Sr}$ in soil water is not only derived from the soil layer, but also originates partly from precipitation. The ${ }^{87} \mathrm{Sr} /{ }^{86} \mathrm{Sr}$ ratios in soil waters at 50 and $100 \mathrm{~cm}$ depths are 0.710606 and 0.709746 , respectively, which fall in between the values for rainwater and soil water (Figure 2), and suggest a decrease with the increasing of soil depth. Conversely, the $\mathrm{Sr}$ concentrations in soil water increase with the soil depth, with levels of 14.4 and $21.7 \mu \mathrm{g} / \mathrm{L}$, respectively. This may suggest that the effect of the bedrock dissolution with low ${ }^{87} \mathrm{Sr} /{ }^{86} \mathrm{Sr}$ signal (Figure 2) on ${ }^{87} \mathrm{Sr} /{ }^{86} \mathrm{Sr}$ ratios in the soil water increase with soil depth. The $\mathrm{Sr}$ isotopes in the soil water (Table 1 and Figure 2) suggest a disequilibrium between the soil exchangeable $\mathrm{Sr}$ and the soil water. The soil water samples are more radiogenic $\left({ }^{87} \mathrm{Sr} /{ }^{86} \mathrm{Sr}\right)$ than those in rainwater and soil exchangeable cation (Table 1 and Figure 2). This implies that when rainwater with a lower ${ }^{87} \mathrm{Sr} /{ }^{86} \mathrm{Sr}$ ratio falls down into the soil layer, the seepage water is affected by the chemical weathering of silicate [12] with more radiogenic ${ }^{87} \mathrm{Sr} /{ }^{86} \mathrm{Sr}$. 


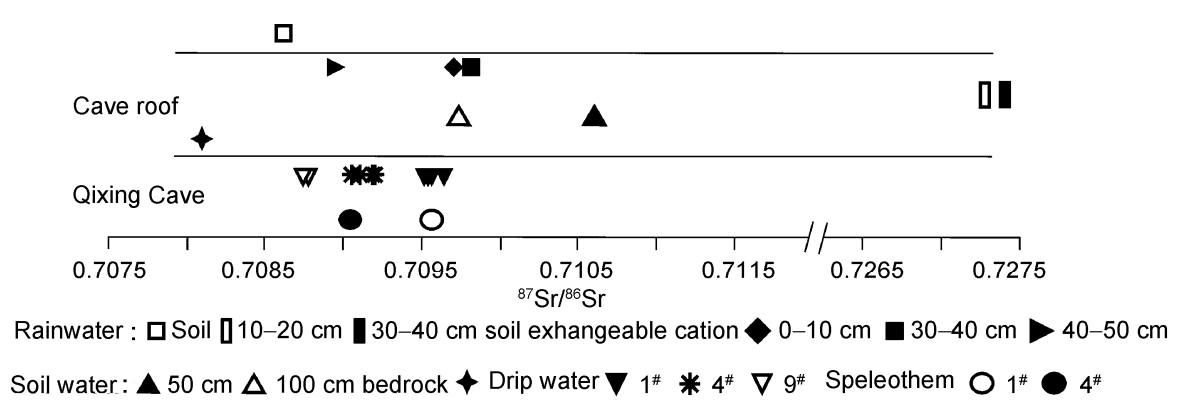

Figure $2{ }^{87} \mathrm{Sr} /{ }^{86} \mathrm{Sr}$ variations of each components in the Qixing Cave system (rainwater $\mathrm{Sr}$ isotopic data from [13,14], refer to sec. 2.2. $1^{\#}$ represents No. 1 drip water, the rest are also deduced by analogy).

This results in an increase in ${ }^{87} \mathrm{Sr} /{ }^{86} \mathrm{Sr}$ ratio in the soil water. However, an incomplete exchange process may occur between soil waters and soil exchangeable cations, since the migration rate of seepage water is rapid, leading to an isotopic disequilibrium between soil waters and the exchange pool [16]. A similar conclusion was also drawn by other research groups [17].

In summary, the $\mathrm{Sr}$ concentrations and isotopic signals in soil water result from interactions between the silicate and the soil exchangeable cations in the soil layer, when rainwater with a low ${ }^{87} \mathrm{Sr} /{ }^{86} \mathrm{Sr}$ ratio infiltrates the soil layer. Soil water results from interactions between different components and the soil system is very complicated. Soil water is a direct source for drip water and can, therefore, be used as an end-member which represents the soil system overlying the QXC. The soil layer is relatively continuous, but its thickness is inconsistent $(6-180 \mathrm{~cm})$, averaging at $33 \mathrm{~cm}$. Furthermore, variations in ${ }^{87} \mathrm{Sr} /{ }^{86} \mathrm{Sr}$ ratio in the soil exchangeable pool and soil are not distinct at soil depths more than $10 \mathrm{~cm}$ from the interface between the bedrock and soil. This suggests the minimal effect of bedrock dissolution with low ${ }^{87} \mathrm{Sr} /{ }^{86} \mathrm{Sr}$ values. It is, therefore, reasonable that the soil water at the $50 \mathrm{~cm}$ depth could be studied as an output end-member to represent the soil layer overlying the cave, whose ${ }^{87} \mathrm{Sr} /{ }^{86} \mathrm{Sr}$ ratio is 0.710606.

\subsection{Sources in drip waters and their implications}

In the QXC, the mean ${ }^{87} \mathrm{Sr} /{ }^{86} \mathrm{Sr}$ ratios in the $1^{\#}, 4^{\#}$ and $9^{\#}$ are $0.709568,0.709139$ and 0.708761 , respectively (Table 2), which fall in between the soil water and bedrock levels. There is a remarkable positive linear correlation between the ${ }^{87} \mathrm{Sr} /{ }^{86} \mathrm{Sr}$ ratios and the reciprocal of the $\mathrm{Sr}$ concentrations $(1 / \mathrm{Sr}$ ) in drip waters (Figure 3$)$. Although a previous study [7] notes that there is a PCP process when the seepage water transfers in the vadose zone overlying the $\mathrm{QXC}$, the partition coefficients for $\mathrm{Mg}$ and $\mathrm{Sr}\left(\mathrm{Tr} / \mathrm{Ca}_{\mathrm{CaCO}_{3}}=\mathrm{K}_{\mathrm{Tr}}\right.$ $(\mathrm{Tr} / \mathrm{Ca})_{\text {solution}}, \mathrm{Tr}$ denotes $\mathrm{Mg}$ or $\mathrm{Sr}$ ) are considerably smaller than 1 in solution $[18,19]$. This means the Sr concentrations in seepage water are not significantly affected by any PCP processes. The strong positive relationship between ${ }^{87} \mathrm{Sr} /{ }^{86} \mathrm{Sr}$ ratios and 1/Sr in drip water (Figure 3) suggest that the ions in drip water are predominantly from the soil layer (soil water) and bedrock overlying the cave. Importantly, this is consistent with the two end-members model. The model can be used to calculate the relative contribution rates of soil water and bedrock to drip water [20,21].

Here, we have assumed that the mass fraction of $\mathrm{Sr}$ derived from soil water $(\mathrm{S})$ at $50 \mathrm{~cm}$ depth soil is $X(\%)$, and that of bedrock dissolution $(\mathrm{R})$ is $(1-X)(\%)$. That is, the ${ }^{87} \mathrm{Sr} /{ }^{86} \mathrm{Sr}$ ratios in drip water (D), as a component mixture from soil water and bedrock dissolution, can be expressed as

$$
\left({ }^{87} \mathrm{Sr} /{ }^{86} \mathrm{Sr}\right)_{\mathrm{D}}=X\left({ }^{87} \mathrm{Sr} /{ }^{86} \mathrm{Sr}\right)_{\mathrm{S}}+(1-X)\left({ }^{87} \mathrm{Sr} /{ }^{86} \mathrm{Sr}\right)_{\mathrm{R}} .
$$

We then get

$$
\begin{aligned}
X= & {\left[\left({ }^{87} \mathrm{Sr} /{ }^{86} \mathrm{Sr}\right)_{\mathrm{D}}-\left({ }^{87} \mathrm{Sr} /{ }^{86} \mathrm{Sr}\right)_{\mathrm{R}}\right] / } \\
& {\left[\left({ }^{87} \mathrm{Sr} /{ }^{86} \mathrm{Sr}\right)_{\mathrm{S}}-\left({ }^{87} \mathrm{Sr} /{ }^{86} \mathrm{Sr}\right)_{\mathrm{R}}\right] \times 100 \% . }
\end{aligned}
$$

The relative proportions from the two main sources for $1^{\#}, 4^{\#}$ and $9^{\#}$ have been estimated and presented in Table 2 using eq. (2). There are distinct differences in the relative contributions from soil water and bedrock dissolution

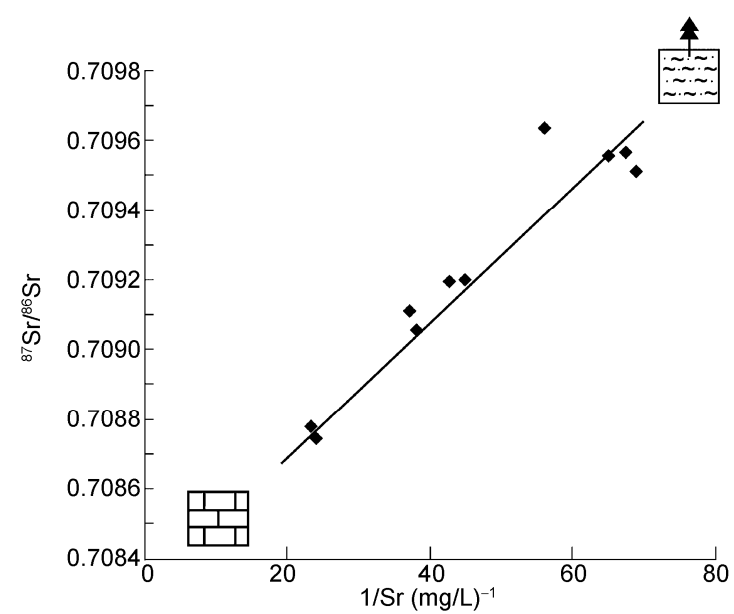

Figure 3 The linear positive relationship between $\left({ }^{87} \mathrm{Sr} /{ }^{86} \mathrm{Sr}\right)$ and $(1 / \mathrm{Sr})$ for drip water. 
Table 2 Relative proportions from two sources and $\delta^{13} \mathrm{C}_{\text {DIC }}$ values in drip water

\begin{tabular}{lccc}
\hline & $1^{\#}$ & $4^{\#}$ & $9^{\#}$ \\
\hline${ }^{87} \mathrm{Sr}^{86} \mathrm{Sr}_{\text {mean }}$ & 0.709568 & 0.709139 & 0.708761 \\
$X_{\text {bedrock }}(\%)$ & 40.8 & 57.6 & 72.4 \\
$X_{\text {soil }}(\%)$ & 59.2 & 42.4 & 27.6 \\
$\delta^{13} \mathrm{C}_{\text {DIC }}(\% o)$ & $-4.5(-6.6--2.7)$ & $-8.6(-9.5--7.0)$ & $-9.3(-9.8--9.2)$ \\
\hline
\end{tabular}

for different drip waters. This may suggest that the extent of interaction between seepage water and bedrock is different along different flow-routes, due to different residence times in the unsaturated zone overlying the cave [22].

Table 2 shows that the soil water affects the drip water in all drip sites, although the relative contribution rates from soil water vary at different drip sites. There is no obvious variability in the structure of the bedrock overlying the cave with speleothems growing over a relative short time scale (less than several hundred thousand years). This suggests the corresponding flow path of seepage water for drip water has not obviously changed over the past several hundred thousand years, which means the relative proportion from bedrock dissolution to drip water is also unchanged. However, the strontium isotopic compositions in bedrock are generally constant, and the ${ }^{87} \mathrm{Sr} /{ }^{86} \mathrm{Sr}$ ratios in drip waters are inherited well by their corresponding speleothems (Table 1 and Figure 2). This may suggest that the $\mathrm{Sr}$ isotopic signals in drip water/speleothem primarily record the $\mathrm{Sr}$ isotopic signals in soil. A similar conclusion has also been reported by other researchers [22]. In this study area, the weathering crust (soil) of carbonate is mainly made up of silicate [12], which has more radiogenic strontium (high ${ }^{87} \mathrm{Sr} /{ }^{86} \mathrm{Sr}$ ratio) than carbonate [23]. Therefore, if the chemical weathering intensity of soils overlying a cave increases, then more silicate components would be dissolved and more $\mathrm{Sr}$ ions in the soil water would originate from silicate components. In short, the $\mathrm{Sr}$ isotopic signals in cave drip water/speleothem can reflect the chemical weathering intensity of the soil, and act as an indicator of monsoon intensity in the study area $[3,24]$.

\subsection{The relationship between ${ }^{87} \mathrm{Sr} /{ }^{86} \mathrm{Sr}$ ratios and $\delta^{13} \mathrm{C}_{\mathrm{DIC}}$ values in drip water}

Our previous studies have indicated that $\delta^{13} \mathrm{C}_{\mathrm{DIC}}$ signals could be affected by bedrock (carbonate) dissolution and $\mathrm{PCP}$ processes in the unsaturated zone overlying the QXC, when soil water transforms to drip water [7]. Site $1^{\#}$, with a heavier $\delta^{13} \mathrm{C}_{\mathrm{DIC}}$ value is classified as Group I, with a $\delta^{13} \mathrm{C}_{\mathrm{DIC}}$ value $4.5 \%$ - $5.7 \%$ o heavier than that in soil water. This suggests that $\delta^{13} \mathrm{C}_{\text {DIC }}$ value for $1^{\#}$ is dominated mainly by bedrock dissolution and PCP processes. However, the $\delta^{13} \mathrm{C}_{\text {DIC }}$ values in the $4^{\#}$ and $9^{\#}$ of Group II were only $0.6 \%-1.6 \%$ o heavier than that of soil water, which is less affected by bedrock dissolution and PCP processes [7]. Due to the bed- rock having a higher $\delta^{13} \mathrm{C}$ value $(1.8 \%$ ) and the preferential degassing of ${ }^{12} \mathrm{CO}_{2}$ over ${ }^{13} \mathrm{CO}_{2}$ in the PCP process, the $\delta^{13} \mathrm{C}_{\mathrm{DIC}}$ value in drip water would increase when both processes are occurring. It is impossible to distinguish the effects of bedrock dissolution and PCP processes based on the $\delta^{13} \mathrm{C}_{\text {DIC }}$ values of drip water, using only $\mathrm{C}$ isotope and hydrological data. Unlike the $\mathrm{C}$ stable isotopes $\left({ }^{13} \mathrm{C}\right.$ and $\left.{ }^{12} \mathrm{C}\right)$, $\mathrm{Sr}$ has a higher relative atomic mass, and the ratio of ${ }^{87} \mathrm{Sr}$ and ${ }^{86} \mathrm{Sr}$ is lower. Consequently, there is negligible $\mathrm{Sr}$ isotopic fractionation in the processes of seepage water movement and transformation in the unsaturated zone overlying the cave. The ${ }^{87} \mathrm{Sr} /{ }^{86} \mathrm{Sr}$ ratio is primarily controlled by the relative proportions of different sources. Sr isotope signals $\left({ }^{87} \mathrm{Sr} /{ }^{86} \mathrm{Sr}\right.$ ratio), which are usually used as tracing sources in the geochemical field, are a potential tool to distinguish between bedrock dissolution and PCP processes.

In this study, the $\mathrm{Sr}$ isotope composition reveals that there is not a one-to-one positive correlation between the $\delta^{13} \mathrm{C}_{\text {DIC }}$ values in drip water and the contribution rates of bedrock dissolution. By contrast, the $\delta^{13} \mathrm{C}_{\text {DIC }}$ value in $1^{\#}$ is the heaviest $(-4.5 \%$ o), where the contribution rate from bedrock dissolution is the lowest. In $9^{\#}$, bedrock dissolution is the highest, and its $\delta^{13} \mathrm{C}_{\text {DIC }}$ value is the lightest (-9.3\%o). The contribution rate from bedrock dissolution in $4^{\#}$ is higher than that in $1^{\#}$, and lower than that in $9^{\#}$, but its $\delta^{13} \mathrm{C}_{\text {DIC }}$ value is significantly lighter than that for $1^{\#}$ by up to $4 \%$ and a little heavier than that for $9^{\#}$ (Table 2). Therefore, according to the relationship between ${ }^{87} \mathrm{Sr} /{ }^{86} \mathrm{Sr}$ ratio and the $\delta^{13} \mathrm{C}_{\text {DIC }}$ values in drip water, when seepage water moves from the soil layer into the cave, the effect of inorganic carbon from the bedrock dissolution is not the main factor that results in different $\delta^{13} \mathrm{C}_{\mathrm{DIC}}$ values across the different drip sites of QXC. This suggests that PCP processes are the main factor in the processes discussed above. Similar conclusions were drawn by other scientists $[25,26]$.

\section{Conclusions}

This study indicates that the differences in ${ }^{87} \mathrm{Sr} /{ }^{86} \mathrm{Sr}$ ratio across different components are distinct in the QXC, which provides a good opportunity for analyzing the relationship between them. On the basis of the remarkable differences in ${ }^{87} \mathrm{Sr} /{ }^{86} \mathrm{Sr}$ ratio between different drip waters and previous studies $[8,9]$, the different flow paths of seepage water result in a variation in residence times and hydro-geological processes in the unsaturated zone overlying the cave. This would affect the sources of drip water, leading to the different relative proportions from bedrock dissolution for $1^{\# \text {, }}$ $4^{\#}$ and $9^{\#}$, which were $40.8 \%, 57.6 \%$ and $72.4 \%$, respectively. Although the ${ }^{87} \mathrm{Sr} /{ }^{86} \mathrm{Sr}$ ratios between the drip water and its corresponding speleothem are a little different in $4^{\#}$, the speleothem fundamentally inherits the $\mathrm{Sr}$ isotopic signals from the drip water. In addition, the source of the drip 
waters and their corresponding speleothems are derived predominantly from the soil layer and bedrock overlying the cave. There are few other sources in this study area, suggesting that the different relative proportions from the soil layer and bedrock may result from changes to the ${ }^{87} \mathrm{Sr} /{ }^{86} \mathrm{Sr}$ ratios in the drip water and speleothem. As a result, it is feasible to use $\mathrm{Sr}$ isotopic signals in the speleothem as an indicator for the chemical weathering intensity of soil, and consequently as a monsoon proxy in this study area. It is, however, necessary to systemically investigate the effects of hydrogeological processes on climatic and environmental signals in the unsaturated zone overlying the cave, when using ${ }^{87} \mathrm{Sr} /{ }^{86} \mathrm{Sr}$ ratios in the speleothem model past climates and environments. The relationship between ${ }^{87} \mathrm{Sr} /{ }^{86} \mathrm{Sr}$ ratios and $\delta^{13} \mathrm{C}_{\mathrm{DIC}}$ values in drip waters indicates that the $\delta^{13} \mathrm{C}_{\mathrm{DIC}}$ values in drip water are controlled principally by a PCP process, and are less affected by bedrock dissolution.

We are grateful to the editor of Chinese Science Bulletin for thoughtful editorial handing and anonymous reviewers for their constructive comments. This work was supported by the Orientation Project of Knowledge Innovation Program of the Chinese Academy of Sciences (KZCX2-YW-306) and the International Partnership Project of the Chinese Academy of Sciences, the National Basic Research Program of China (2006CB403200), the National Natural Science Foundation of China (90202003), and the Personnel Training Project (Western Doctor) of West Light Foundation of the Chinese Academy of Sciences.

1 Avigour A, Magaritz M, Issar A, et al. Sr isotope study of vein and cave calcites from southern Israel. Chem Geol, 1990, 82: 69-81

2 Verheyden S, Keppens E, Fairchild I J, et al. $\mathrm{Mg}$, $\mathrm{Sr}$ and $\mathrm{Sr}$ isotope geochemistry of a Belgian Holocene speleothem: Implications for paleoclimate reconstructions. Chem Geol, 2000, 169: 131-144

$3 \mathrm{Li} \mathrm{H} \mathrm{C,} \mathrm{Ku} \mathrm{T} \mathrm{L,} \mathrm{You} \mathrm{C} \mathrm{F,} \mathrm{et} \mathrm{al.}{ }^{87} \mathrm{Sr} /{ }^{86} \mathrm{Sr}$ and $\mathrm{Sr} / \mathrm{Ca}$ in speleothems for paleoclimate reconstruction in Central China between 70 and 280 ka ago. Geochim Cosmochim Acta, 2005, 69: 3933-3947

4 Zhou H Y, Feng Y X, Zhao J X, et al. Deglacial variations of Sr and ${ }^{87} \mathrm{Sr} /{ }^{86} \mathrm{Sr}$ ratio recorded by a stalagmite from Central China and their association with past climate and environment. Chem Geol, 2009, 268: 233-247

5 Bar-Matthews M, Ayalon A, Kaufman A, et al. The Eastern Mediterranean paleoclimate as a reflection of regional events: Soreq cave, Israel. Earth Planet Sci Lett, 1999, 166: 85-95

6 Frumkin A, Stein M. The Sahara-East Mediterranean dust and climate connection revealed by strontium and uranium isotopes in a Jerusalem speleothem. Earth Planet Sci Lett, 2004, 217: 451-464

7 Wang S J, Luo W J, Liu X M, et al. Effects of hydrogeochemistry on $\delta^{13} \mathrm{C}_{\text {DIC }}$ values of drip water in Qixing Cave, Guizhou, China and their implications (in Chinese). Earth Sci Front, 2009, 16: 66-76

8 Zhou Y C, Wang S J, Xie X N, et al. Significance and dynamics of drip water responding to rainfall in four caves of Guizhou, China.
Chinese Sci Bull, 2005, 50: 155-162

9 Zhou Y C, Wang S J. Drips hydrogeochemical characteristics of Qixing cave and its implications (in Chinese). Hydrogeol Eng Geol, 2006, 33: 52-57

10 Peng Z C, Zhang Z F, Cai Y J, et al. The paleoclimatic records from the late Pleistocene stalagmite in Qixing Cave of Guizhou (in Chinese). Quat Sci, 2002, 22: 273-282

11 Cai Y J, Peng Z C, An Z S, et al. The $\delta^{18} \mathrm{O}$ variation of a stalagmite from Qixing Cave, Guizhou Province and indicated climate change during the Holocene. Chinese Sci Bull, 2001, 46: 1904-1908

12 Wang S J, Sun C X, Feng Z G, et al. Mineralogical and geochemical characteristics of the limestone weathering profile in Jishou, westhern Hunan Province, China (in Chinese). Acta Mineral Sin, 2002, 22: 1929

13 Han G L, Liu C Q. Strontium isotope and major ion chemistry of the rainwaters from Guiyang, Guizhou Province, China. Sci Total Environ, 2006, 364: 165-174

14 Han G L, Tang Y, Wu Q X, et al. Chemical and strontium isotope characterization of rainwater in karst virgin forest, Southwest China. Atmos Environ, 2010, 44: 174-181

15 Luo W J. Geochemistry characteristics of stable isotopes in karst cave systems and their environmental implications (in Chinese). Dissertation for the Doctoral Degree. Guiyang: Institute of Geochemistry, Chinese Academy of Sciences, 2007. 58-63

16 Bullen T, White A, Blum A, et al. Chemical weathering of a soil chronosequence on granitoid alluvium: II. Mineralogic and isotopic constraints on the behavior of strontium. Geochim Cosmochim Acta, 1997, 61: 291-306

17 Pett-Ridge J C, Derry L A, Barrows J K. Ca/Sr and ${ }^{87} \mathrm{Sr} /{ }^{86} \mathrm{Sr}$ ratios as tracers of $\mathrm{Ca}$ and $\mathrm{Sr}$ cycling in the Rio Icacos watershed, Luquillo Mountains, Puerto Rico. Chem Geol, 2009, 267: 32-45

18 Huang Y M, Fairchild I J. Partitioning of $\mathrm{Sr}^{2+}$ and $\mathrm{Mg}^{2+}$ into calcite under karst-analogue experimental conditions. Geochim Cosmochim Acta, 2001, 65: 47-62

19 Fairchild I J, Treble P C. Trace elements in speleothems as recorders of environmental change. Quat Sci Rev, 2009, 28: 449-468

20 Miller E K, Blum J D, Friedland A J. Determination of soil exchangeable-cation loss and weathering rates using $\mathrm{Sr}$ isotopes. Nature, 1993, 362: 438-441

21 Dijkstra F A, Breemen N V, Jongmans A G, et al. Calcium weathering in forested soils and the effect of different tree species. Biogeochemistry, 2003, 62: 253-275

22 Musgrove M, Banner J L. Controls on the spatial and temporal variability of vadose dripwater geochemistry: Edwards aquifer, central Texas. Geochim Cosmochim Acta, 2004, 68: 1007-1020

23 Han G L, Liu C Q. Water geochemistry controlled by carbonate dissolution: A study of the river waters draining karst-dominated terrain, Guizhou Province, China. Chem Geol, 2004, 204: 1-21

24 Banner J L, Musgrove M, Asmerom Y, et al. High-resolution temporal record of Holocene ground-water chemistry: Tracing links between climate and hydrology. Geology, 1996, 24: 1049-1053

25 Oster J L, Montañez I P, Guilderson T P, et al. Modeling speleothem $\delta^{13} \mathrm{C}$ variability in a Central Sierra Nevada Cave using ${ }^{14} \mathrm{C}$ and ${ }^{87} \mathrm{Sr} /{ }^{86} \mathrm{Sr}$. Geochim Cosmochim Acta, 2010, 74: 5228-5242

26 Johnson K R, Hu C Y, Belshaw N S, et al. Seasonal trace-element and stable-isotope variations in a Chinese speleothem: The potential for high-resolution paleomonsoon reconstruction. Earth Planet Sci Lett, 2006, 244: 394-407

Open Access This article is distributed under the terms of the Creative Commons Attribution License which permits any use, distribution, and reproduction in any medium, provided the original author(s) and source are credited. 